\title{
Perfil socioeconômico dos frequentadores do Parque Estadual Massairo OKamura, 2007
}

\section{Socio-economic profile of visitors of the State Park Massairo Okamura, 2007}

\author{
Perfil socioeconómico de los usuarios del Parque Estatal \\ Massairo Okamura, 2007
}

\author{
Jorge Luiz de Arruda ${ }^{1}$ \\ Josué Ribeiro da Silva Nunes ${ }^{2}$
}

\begin{abstract}
RESUMO
Quando se trabalha com unidades de conservação como o Parque Massairo Okamura, localizado em Cuiabá (Mato Grosso), devem-se estudar também os seus frequentadores e, a partir daí, políticas que possam incrementar o ambiente poderão ser implantados ao longo do tempo. Uma descrição qualitativa e quantitativa foi elaborada com 100 frequentadores do parque e nos trouxe resultados diversos. A localização das residências dos usuários do parque foi eclética, pois foram apresentados moradores dos núcleos habitacionais e de bairros mais afastados, como jardim Vitória, Florianópolis e até mesmo do município vizinho, Várzea Grande. A maioria é constituída de servidores públicos, com nível de escolaridade variando do fundamental incompleto até o superior completo.
\end{abstract}

Palavras-chave: frequentadores; parque estadual; usuários.

\begin{abstract}
When one works with units of conservation as the Massairo Okamura Park, located in Cuiabá (Mato Grosso), its visitors must also be studied, and then it's possible to propose policies that can develop the environment in the long term. A qualitative and quantitative description of 100 visitors of the park was elaborated and showed us various results. The location of the park visitors' residences was eclectic, showing that some lived in the housing nuclei and others came from more distant neighborhoods, such as Jardim Vitória, Florianópolis and even from the neighboring city, Várzea Grande. The majority of the visitors are public workers, and their education level varies from incomplete basic education to undergraduate.
\end{abstract}

Keywords: visitors; state park; users.

\section{RESUMEN}

Cuando se trabaja con unidades de conservación como el Parque Massairo Okamura, que se encuentra en Cuiabá (Mato Grosso), debería estudiar también a sus visitantes, desde allí políticas que puedan mejorar el medio ambiente pueden ser desplegadas en el tiempo. Una descripción cualitativa y cuantitativa fue preparado con 100 visitantes del parque y el nos ha traído resultados diferentes. La ubicación de las residencias de los usuarios del parque es ecléctico, porque no eran residentes de los núcleos y la vivienda, así como los barrios más alejados como Victory Jardín, Florianópolis, y hasta el vecino municipio, Várzea Grande. La gran mayoría está compuesta de funcionarios públicos, con nivel de educación que van desde básico incompleto hasta superior completo.

Palabras clave: visitantes; parque estatal; los usuarios.

\footnotetext{
${ }_{1}$ Licenciado e Bacharel em Ciências Biológicas pela Universidade de Cuiabá (Unic).

2 Mestre em Ecologia pela UFSCar, Professor da Universidade de Cuiabá e da Universidade do Estado de Mato Grosso; Doutor em Ecologia e Recursos Naturais (UFSCar, 2010).
} 


\section{Introdução}

Quando se trabalha com Unidades de Conservação, como é o caso do Parque Estadual Massairo Okamura, além de identificar os organismos que habitam o local e a dominância fitofisionômica do ambiente, outro fator primordial é a pesquisa de dados dos frequentadores habituais do local (SEGER, 2006).

Conforme Carvalho, Cruz e Nobre (2002), é necessário o desenvolvimento de métodos que permitam a integração $e$ análise de grande número de variáveis, tendo por objetivo a construção de um índice único, ou seja, a construção de um perfil socioeconômico dos frequentadores do parque estadual.

Quando um estudo pretende levantar subsídios como o perfil de usuários, ou seja, de indivíduos da comunidade envolvida, tem de se preocupar com os dados obtidos e sua posterior conclusão (METZ, 2006), pois, em determinado momento, os dados poderão apresentar conflitos que vão do aspecto social até o econômico $e$, nesse momento, tudo aquilo que é citado poderá recair sobre a equipe de trabalho como pontos conflitantes e determinar a suspeição sobre tudo que já foi realizado até o presente momento (SANTOS; COSTA, 2005).

Por outro lado, a caracterização socioeconômica dos grupos populacionais, além de considerar todas as possivieis informações qualitativas, sociológicas e geopolíticas, pode ser abordada com base em informações amplamente acessíveis, como os indicadores do censo demográfico (CARVALHO et al., 1997).
De posse dos resultados de uma entrevista como a realizada dentro do Parque Estadual Massairo Okamura, a compilação e a interpretação exata dos números ofertados nos conduzirão a uma discussão intensa de como vivem e quem são os frequentadores do ambiente. E mais, a reflexão de como é sua percepção em relação a todo o trabalho desenvolvido dentro do parque contribuirá para o mapeamento dos trabalhos que precisam ser melhorados e aqueles que estão sendo apresentados à população de modo correto.

O objetivo deste trabalho foi descrever o perfil socioeconômico dos frequentadores do Parque Estadual Massairo Okamura.

\section{Material e métodos}

Foram realizadas entrevistas com os frequentadores do Parque Estadual Massairo Okamura, para caracterização de aspectos como bairro de origem, grau de escolaridade, percepção do parque e de sua limpeza, e conhecimento relativo à educação ambiental dos visitantes e usuários.

Foi utilizado o método estatístico, cujo principal objetivo é fornecer uma descrição quantitativa e qualitativa de uma sociedade (MARCONI; LAKATOS, 2006). O período de entrevistas foi de 16 a 20 de julho de 2007 e delimitado a 100 (cem) frequentadores do parque estadual.

A partir dos dados coletados, podem-se caracterizar os frequentadores e propor políticas públicas para ser implantadas no local para a sensibilização dos frequentadores para a prática da conservação e, principalmente, da educação ambiental. 
Resultados e discussão

\section{Localização da residência dos entrevistados}

Pode-se constatar, neste caso, que existe uma distribuição bem homogênea quanto aos bairros de origem dos usuários do parque estadual, sendo percebida uma maior parcela (20\%) de moradores oriundos do bairro CPA II. Outros bairros aparecem com $16 \%$, enquanto o bairro Morada do Ouro vem em terceiro lugar, com $15 \%$ (Figura 1).

O bairro CPA II dista cerca de $3 \mathrm{~km}$ do parque e seus moradores vão ao parque quase constantemente, isso sem levar em conta os outros moradores de bairros, como Jardim Vitória, Novo Paraíso I e II, que distam ainda mais do parque.
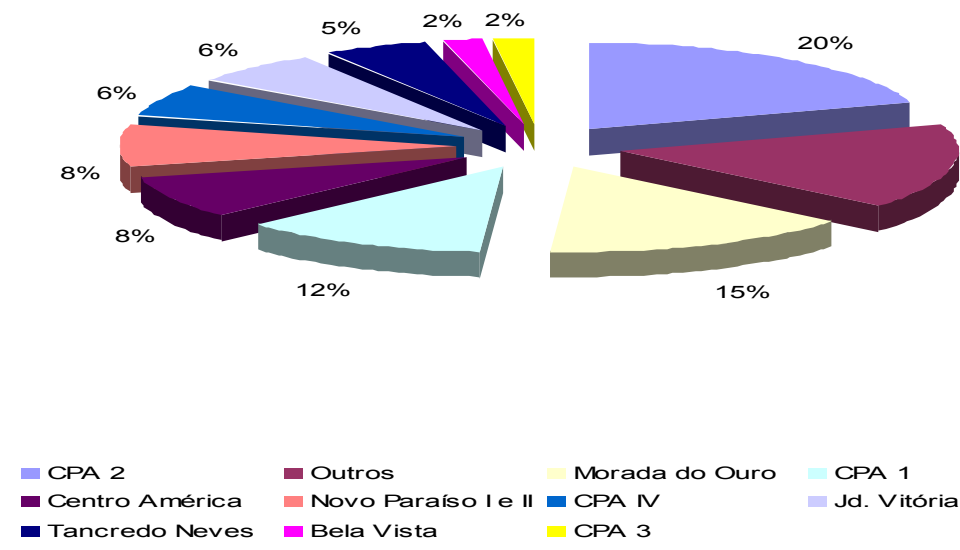

FIGURA 1 - BAIRRO DE ORIGEM DOS FREQUENTADORES DO PARQUE ESTADUAL MASSAIRO OKAMURA

\section{Nível de escolaridade dos entrevistados}

A entrevista permitiu verificar que os frequentadores são de bairros que ficam mais afastados do parque, como é o caso do Jardim Vitória, Paraíso I e II, Centro América, que também são bairros carentes e de periferia e, portanto, uma grande parcela de seus moradores não completou o ensino fundamental (49\%), ou seja, a maioria dos frequentadores são pessoas sim-

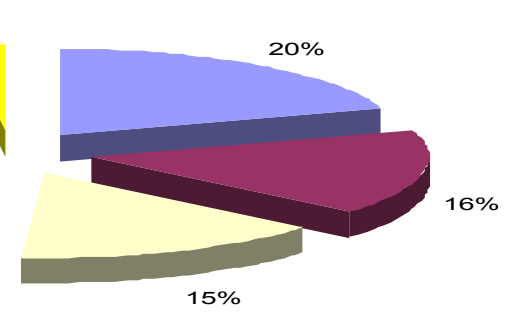

Podemos destacar ainda que, na relação "outros bairros", apareceram moradores do Centro da Capital, do Baú, do Umuarama e inclusive de Várzea Grande. Isso foi verificado a partir das perguntas realizadas aos frequentadores dentro do parque e eles responderam que são servidores públicos estaduais que trabalham no Centro Político Administrativo (CPA) que fica localizado em frente ao parque estadual.

Destaca-se a reconfiguração espacial urbana dos frequentadores do parque e não se pode deixar de lado a herança histórica de um processo de urbanização marcado pela rapidez e pela exclusão social, pois, enquanto alguns alcançaram o sonho da casa própria, por fazer parte de um núcleo social ou político, outros foram excluídos desse sonho (CARVALHO et al., 2001). ples que utilizam o parque como mais um local de lazer e descontração por causa de seu baixo poder aquisitivo e do fato de que seu bairro de origem não conta com áreas de lazer (Figura 2).

Pode-se definir que, dessa grande parcela $(49 \%)$ que disse ter o ensino fundamental incompleto e completo, alguns se enquadram como analfabetos absolutos ou funcionais, ou seja, são pessoas que nunca estudaram, ou que estudaram, mas não consegue sequer ler (BORGES; PINHEIRO, 2002). 
O ensino médio incompleto ou completo aparece com $31 \%$. Podemos destacar, mais uma vez, que tanto os que têm ensino superior quanto médio estão inclusos entre aqueles que citam serem servidores públicos.

Conforme dados da Pesquisa Nacional por Amostra de Domicílios (PNAD) de 1995, o Brasil tinha 66 milhões de trabalhadores, dos quais 49 milhões não eram qualificados, ou seja, tinham apenas a $8^{\mathrm{a}}$ série do ensino fundamental (BARROS et al., 1997).

Deve-se destacar que uma boa parcela (24\%) são pessoas que iniciaram ou concluíram o ensino superior e isso nos dá um perfil de indivíduos que deveriam ser conscientes no em relação aos temas ambientais em voga e utilizar o parque como um local de práticas esportivas e também como ponto de contato com a natureza.

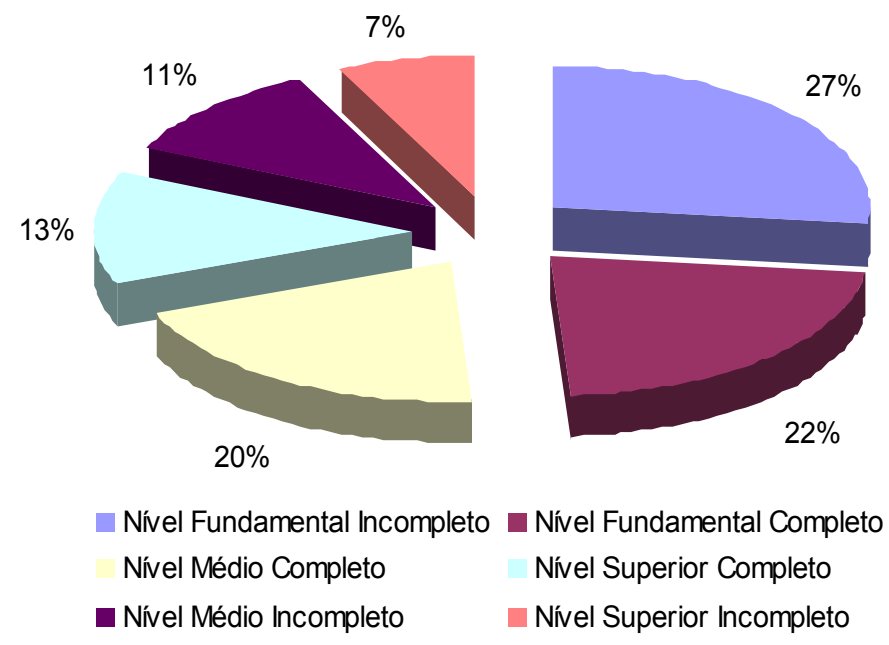

FIGURA 2 - NÍVEL DE ESCOLARIDADE DOS FREQUENTADORES DO PARQUE MASSAIRO OKAMURA

3. Período de frequência de visita ao parque pelos entrevistados

Neste quadro podemos perceber que os usuários do parque, quando são assíduos, passam a frequentá-lo em períodos mais longos, ou seja, de 3 a 5 vezes na semana (69\%). Eles vão ao parque para realizar suas atividades, que vão da caminhada até a corrida. Com isso, podemos concluir que essas pessoas têm um hábito saudável que deveria ser seguido por outros frequentadores (Figura 3).

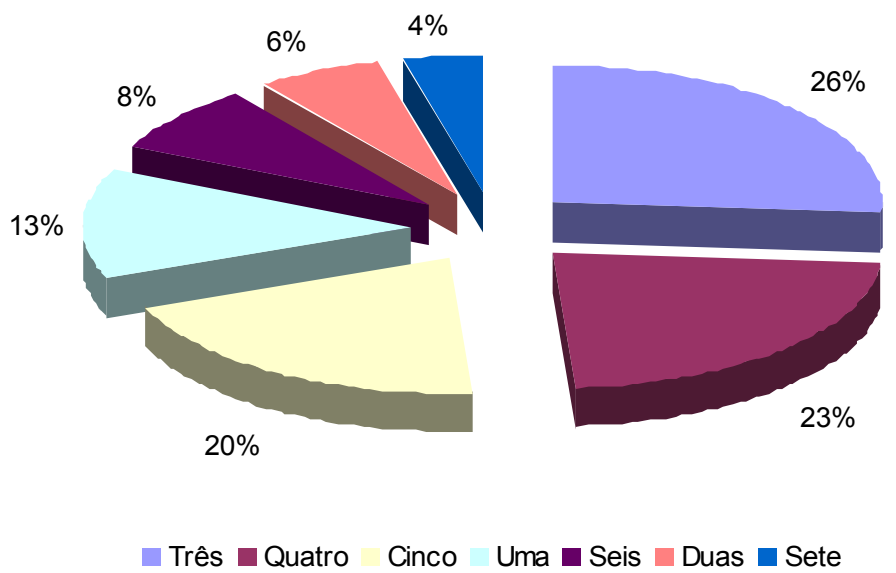

FIGURA 3 - NÍVEL DE FREQUÊNCIA DOS USUÁRIOS DO PARQUE MASSAIRO OKAMURA 


\section{Rendimento salarial dos entrevistados}

Podemos analisar esse quadro da seguinte maneira: a maioria dos entrevistados (40\%) estão enquadrados no quesito servidor público, pois a renda mensal verificada nos órgãos públicos encontra-se na faixa que varia dos 2 aos 5 salários mínimos (Figura 4).

Vinte e dois por cento dos entrevistados recebem apenas um salário mínimo e parece que se pode relacioná-los àquelas pessoas que moram nos bairros mais afastados do parque, pois os bairros próximos ao parque são considerados de renda média ou até alta, sendo estes: Morada do Ouro, CPA 1, 2, 3 e 4.

Deve-se destacar, ainda, que rendimentos de até um salário mínimo são recebidos por empregados com carteira assinada, pelos servidores públicos e, principalmente, pelo setor informal (NERI, 1997; FOGUEL, 1997).

Mas o preocupante neste quadro se verifica no tocante ao quesito "sem rendimento", ou seja, $25 \%$ dos entrevistados encontram-se sem renda salarial, por mais que nesse quesito se possam encontrar aquelas pessoas que dizem ser estudantes, mas, quando se cruzam as informações obtidas chega-se à conclusão de que esses indivíduos "estudantes" podem estar disfarçando uma situação para não se sentirem menosprezados perante a sociedade. Um triste retrato da situação brasileira atual, na qual a falta de estudo e de qualificação profissional eleva ainda mais o quadro do desemprego no país.

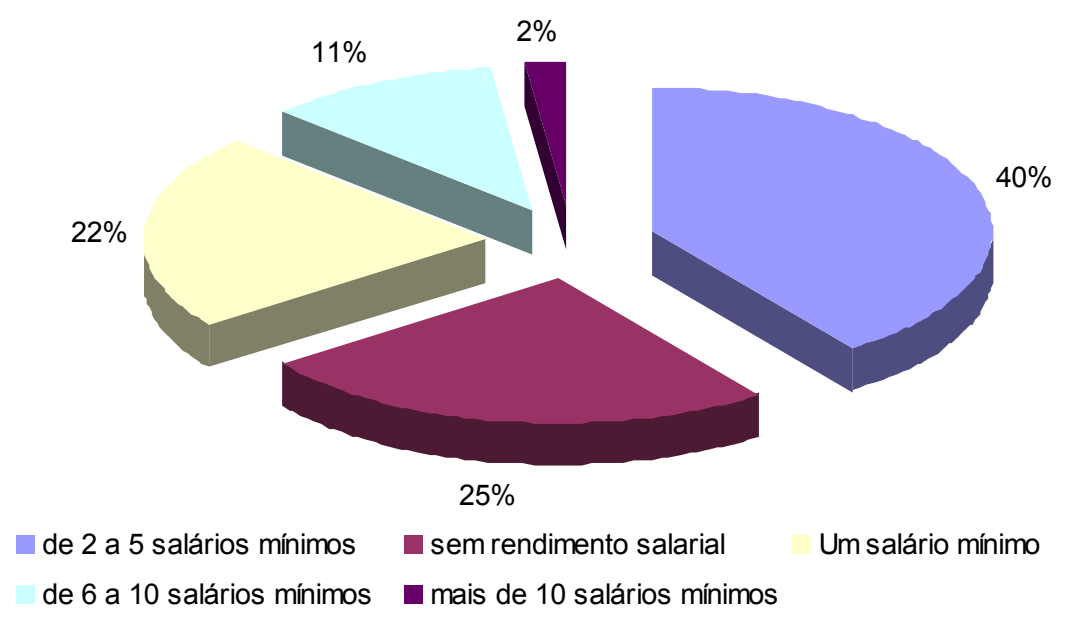

FIGURA 4 - NÍVEL SALARIAL DOS USUÁRIOS DO PARQUE MASSAIRO OKAMURA

\section{Categoria profissional dos entrevistados}

Neste detalhamento chega-se à conclusão de que os maiores usuários do parque são os servidores públicos $(27 \%)$ e, fazendo-se uma somatória do nível de escolaridade com a localização da moradia e a renda salarial, pode-se definir com plena certeza que esses indivíduos são dos núcleos habitacionais localizados perto do parque estadual. Historicamente, esses núcleos são habitados, na sua maioria, por servidores públicos das três esferas administrativas (Figura 5).
Em segundo lugar, encontramos a categoria dos estudantes (23\%), e mais uma vez temos de destacar que, por vezes, o cidadão não admite ou não responde que esteja desempregado por uma questão cultural que envolve o nosso país, ou seja, toda vez que alguém cita que está desempregado, a maioria dos comentários que seguem confirmam que o indivíduo vive à custa do outro, e assim é bem mais fácil omitir o desemprego e dizer que optou pelo estudo para garantir um futuro melhor. No final da entrevista, encontramos aqueles usuários 
que se identificaram como aposentados (3\%), mas nesse ponto podemos destacar que a baixa parcela dessa clientela muitas vezes não está na disposição física e mental, e sim nos obstáculos que o parque oferece para essas pessoas, pois as pistas do parque são, em determinados pontos,
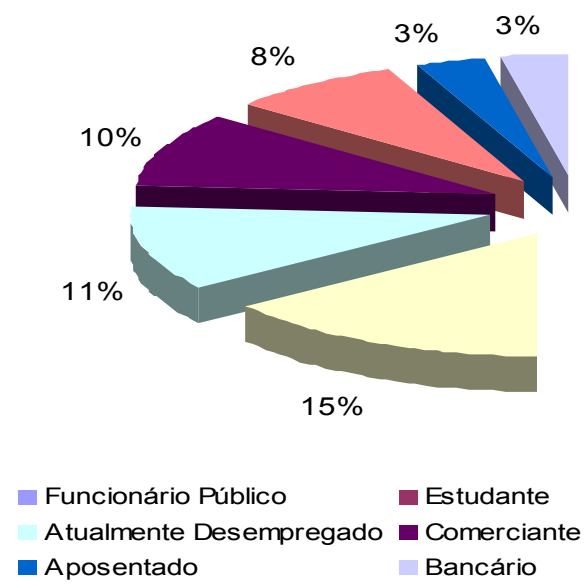

de difícil acesso para essas pessoas: nelas temos descidas ou subidas muito íngremes. Além disso, no período das chuvas, em certos pontos, as pistas ficam escorregadias, por demais perigosas para idosos ou pessoas portadoras de qualquer deficiência física ou limitação.

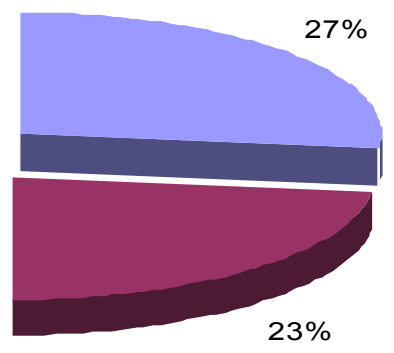

$$
\begin{aligned}
& \text { Autônomo } \\
& \text { Comerciário }
\end{aligned}
$$

\section{FIGURA 5 - PERFIL PROFISSIONAL DOS USUÁRIOS DO PARQUE MASSAIRO OKAMURA}

\section{Conhecimento sobre educação ambiental entre os entrevistados}

Quanto à questão ambiental, a primeira coisa que vem à mente das pessoas é a natureza, a partir daí torna-se fácil perguntar se já ouviu ou não falar sobre educação ambiental, como se pode constatar na Figura 6: 95\% dos entrevistados responderam que sim.

Falar de educação ambiental dentro de um parque estadual é provocar o cidadão ali presente, haja vista que mesmo aqueles que responderam que nunca ouviram falar sobre o assunto $(5 \%)$ provavelmente já teriam tido alguma experiência com o tema, mesmo que indireta, pois atualmente tudo que é consumido no mundo globalizado passa pelo referencial ambiental, que vai desde a pergunta "se é natural ou transgênico" ou "qual é a sua origem".
Isso se dá principalmente pelo fato de que a educação ambiental está inserida diariamente na mídia eletrônica, sendo assim, aquelas pessoas que dizem que nunca ouviram falar sobre o tema podem estar apenas querendo "fugir das responsabilidades" como agentes conscientes e participativos de uma comunidade. Vale lembrar ainda que, em 1992, o Brasil foi palco da Conferência Mundial do Meio Ambiente, denominada ECO/92 e, a partir desse ano, os termos meio ambiente, educação ambiental, ecologia e transgênico passaram a ser mais conhecidos pela população brasileira de um modo geral.

Conforme Santos (2002), a educação ambiental no Brasil surge como estratégia para superar o paradigma da racionalidade instrumental que operou no Brasil e no mundo, ou seja, busca uma maior participação de todos quanto à emancipação e à diversidade que se encontra no mundo atualmente. 


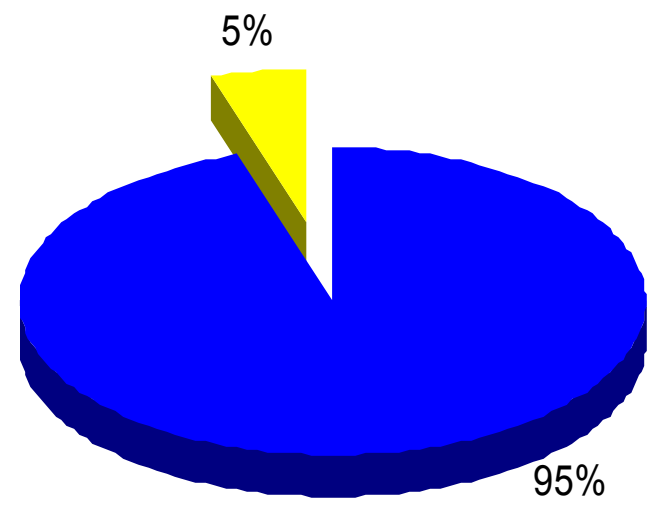

- Sim Não

FIGURA 6 - CONHECIMENTO SOBRE A EDUCAÇÃO AMBIENTAL DOS USUÁRIOS DO PARQUE MASSAIRO OKAMURA

7. Avaliação dos entrevistados ao Parque Massairo Okamura

Neste ponto, podemos concluir que os usuários do parque optaram por uma nota intermediária, que vai dos 5 aos 7 pontos (62\%), por entenderem que o parque precisa de algumas adaptações de ordem estrutural, como adequações nas pistas para receber, principalmente, pessoas idosas ou portadores de necessidades especiais (Figura 7).

Aqueles que dão nota que variam de 8 a $10(23 \%)$, acredita-se serem pessoas que necessitam de um mínimo de conforto e estrutura para se sentirem realizadas, são aquelas pessoas que, quando chegam a algum lugar e o encontram apenas limpo dentro de seu campo de visão, isso já lhes basta, e sobre outros pontos que elas não observaram, não tecem nenhum comentário.

Quanto aos 15\% de insatisfeitos com o local, podemos destacar que ou estão fazendo comparação com outro local visitado ou apenas estão dando uma opinião meramente parcial do momento em que se encontravam dentro do parque estadual.

Vale destacar, porém, que as médias das notas dadas ficaram próximas umas das outras, principalmente nos quesitos que vão de 0 a 4 e de 8 a 10. Avaliar o parque com uma nota entre 0 a 4 depende muito da consciência e sensibilidade de cada entrevistado, ou seja, se ele estiver em um bom dia, a avaliação poderá ser outra, se comparada a um dia ruim.

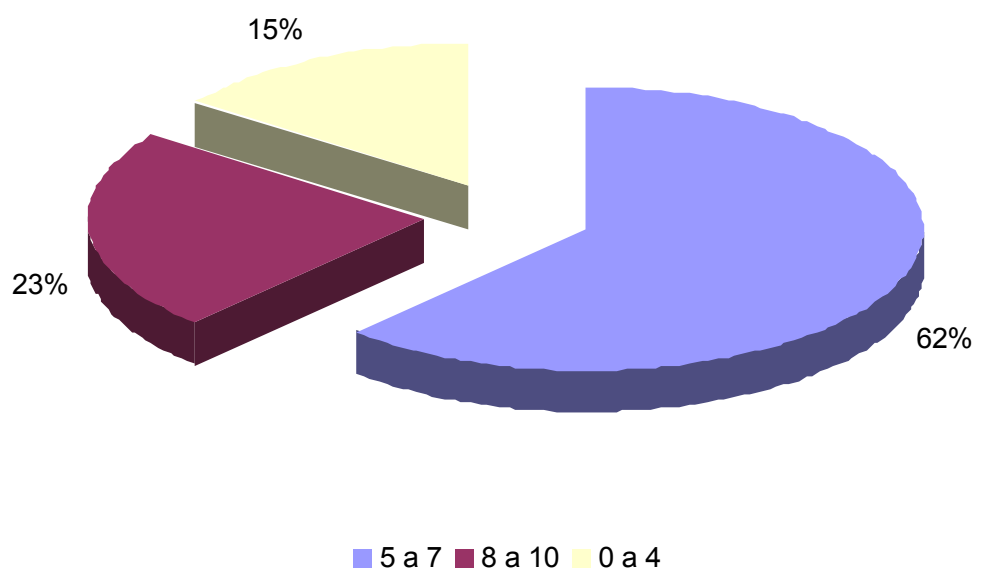

FIGURA 7 - AVALIAÇÃO SOBRE O PARQUE MASSAIRO OKAMURA 
8. Avaliação dos entrevistados quanto à limpeza do parque

Quarenta e um por cento dos entrevistados acham o parque estadual limpo, mas que isso pode ser melhorado ao longo do tempo. Essa reflexão vem sempre no período matutino, quando a equipe da limpeza está iniciando as suas atividades e é comum encontrar as pistas sujas, com folhas e sementes que caem das árvores, pois, ao longo do dia, pode-se perceber pouco material jogado no chão, sendo às vezes avistados pneus, embalagens de bolachas e outros artigos, tais como preservativos, dentro da área verde do parque (Figura 8).

Mas não se deve culpar apenas a equipe de limpeza e a direção quanto a esses fatos relatados, e sim a todos os frequentadores do parque, que não contribuem para a limpeza, haja vista que há lixeiras ao longo das pistas para que o lixo possa ser recolhido.

Quanto a pneus velhos e isopores encontrados principalmente dentro das nascentes localizadas no parque, podemos dizer que a consciência e a sensibilidade daqueles que fazem isso está prejudicada por questões sociais ou até mesmo por falta de uma educação familiar, pois, quando citamos educação, não podemos comentar apenas a educação institucional ofertada pelos governantes, mas devemos citar a educação familiar, que é o princípio e a base de todos os cidadãos. Quanto aos frequentadores que responderam que o parque está sujo (35\%), o que se conclui é que, em determinado período, talvez o parque tenha ficado sem uma equipe de limpeza por motivos administrativos, e somente após a entrada de uma nova equipe o parque passou a ser novamente limpo, tornando-se adequado para a visitação.

\section{AVALIAÇÃO SOBRE A LIMPEZA DO PARQUE MASSAIRO OKAMURA}

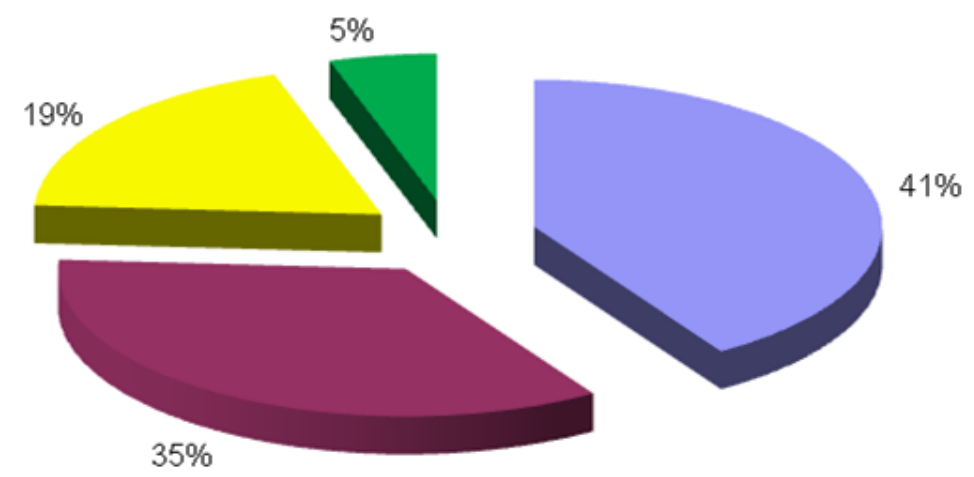

\footnotetext{
= Limpo, mas a manutenção pode ser melhorada

- Sujo, parecendo abandonado

Razoável, faltando manutenção

- Limpo
}

FIGURA 8 - AVALIAÇÃO SOBRE A LIMPEZA DO PARQUE MASSAIRO OKAMURA

Considerações finais

Com os dados obtidos, encontramos um público bem eclético que frequenta o parque estadual, com relação a escolaridade, renda, proximidade do parque, entre outros.
O destaque neste trabalho é dado para a correlação entre os dados, ou seja, pode-se concluir que, além de os frequentadores serem, na sua maioria, moradores dos núcleos habitacionais (CPA I, II, III, IV e Morada do Ouro), eles são servidores públicos, pois estes núcleos habitacionais foram construídos primeiramente 
para receber os servidores públicos estaduais que trabalhavam no Centro Político Administrativo (CPA) no final da década de 1970.

Nessa mesma linha, pode-se concluir que, por serem servidores públicos, os frequentadores do parque têm de ter um nível de escolaridade entre o fundamental completo e o superior completo, isto porque a Constituição Federal de 1988 determinou que, para ser servidor público, o cidadão deverá primeiro passar por concurso público e, na sua maioria, esses concursos determinam que o nível de escolaridade deve ser o Ensino Médio Completo ou o Superior Completo.

A grande surpresa da entrevista ficou pelo quesito assiduidade, ou seja, a frequência com que os usuários do parque o visitam, perfazendo entre 3 e 5 dias na semana. Como os profissionais da área da saúde recomendam uma frequência de, no mínimo, 3 vezes por semana, podemos classificar essa habitualidade como excelente.

Quanto à avaliação da infraestrutura do parque pelos entrevistados, pode-se destacar que, para $35 \%$ dos entrevistados, o parque estava sujo, mas destacamos que, por causa da ausência da equipe de limpeza no parque (por conta da quebra de contrato da empresa terceirizada), os frequentadores repassaram essa visão de abandono para a entrevista; mas, com o decorrer dos meses, o parque voltou a se apresentar limpo e próprio para as visitações públicas.

Concluímos, com esse resultado, que os frequentadores do parque utilizam-no para as práticas esportivas como caminhada e corrida, para visitações a locais conservados e preservados, para estar em contato com a natureza e os seres vivos que habitam o local, e muitos o frequentam em virtude da baixa renda, pois o parque possibilita a eles e a suas famílias uma oportunidade melhor de realizar uma atividade física em contato com a natureza.

\section{REFERÊNCIAS}

BARROS, Ricardo Paes de; FOGE, Miguel; MENDONÇA, Rosane. Perspectivas para o mercado de trabalho brasileiro ao longo da próxima década. Rio de Janeiro: Ipea, 1997.

BRASIL, Ministério da Justiça do. Constituição Federal de 1988. Brasília: Ministério da Justiça. Disponível em: <http://www.mj.gov.br>. Acesso em: 10/11/2007.

BORGES, Livia de Oliveira; PINHEIRO, José Q. Estratégias de coleta de dados com trabalhadores de baixa escolaridade. Natal: Universidade Federal do Rio Grande do Norte, 2002.

CARVALHO, Marilia Sá; CRUZ, Oswaldo Gonçalves; NOBRE, Flávio Fonseca. Perfil de risco: método multivariado de classificação sócio-econômica de microáreas urbanas os setores censitários da região metropolitana do Rio de Janeiro. Rio de Janeiro: Escola Nacional de Saúde Pública, 2002.

CARVALHO, Inaiá Maria Moreira de; ALMEIDA, Paulo Henrique de; AZEVEDO, José Sérgio Gabrielli de. Dinâmica metropolitana e estrutura social em Salvador. Salvador: Universidade Federal da Bahia, 2001.

FOGUEL, M. Uma análise dos efeitos do salário mínimo sobre o mercado de trabalho no Brasil. Dissertação (Mestrado) - Departamento de Economia, Pontifícia Universidade Católica do Rio de Janeiro, Rio de Janeiro, 1997.

MARCONI, Marina de Andrade; LAKATOS, Eva Maria. Metodologia científica. 4. ed. São Paulo: Atlas, 2006. p. 93.

METZ, Jaques. Um modelo de ferramenta para a geração do arquivo SIntegra. Novo Hamburgo: Centro Universitário Feevale, 2006.

NERI, M. O reajuste do salário mínimo de maio de 1995. In: ENCONTRO BRASILEIRO DE ECONOMETRIA, 19. 1997, Recife. Anais... Recife: SBE, 1997.

SANTOS, B. de S. Para uma sociologia das ausências e uma sociologia das emergências. Revista Crítica de Ciências Sociais, Coimbra, n. 63, 2002.

SANTOS, Rubens da Costa; COSTA, Francisco José da. As ações de responsabilidade social no varejo brasileiro: uma análise exploratória. Revista Faces, Belo Horizonte, 2005.

SEGER, Celso Darci. Utilização dos recursos naturais da paisagem para o planejamento de um circuito de ecoturismo na Reserva Volta Velha - Itapoá - Santa Catarina. Dissertação (Mestrado em Conservação da Natureza) Universidade Federal do Paraná, Curitiba, 2006.

Texto aprovado em 18 de novembro de 2010. 